\section{A) Check for updates}

Cite this: Dalton Trans., 2019, 48, 17605

Received 12th September 2019, Accepted 12th November 2019

DOI: $10.1039 / c 9 d t 03660 a$

rsc.li/dalton

\title{
Investigation of the rhodium-catalyzed hydroboration of NHC-boranes: the role of alkene coordination and the origin of enantioselectivity $\dagger$
}

\author{
Paola Nava, (D) * Momar Toure, Amel Abdou Mohamed, Jean-Luc Parrain (iD and \\ Olivier Chuzel (D) *
}

\begin{abstract}
The mechanism of the intramolecular enantioselective rhodium(I)-catalyzed hydroboration of $\mathrm{NHC}$ boranes is investigated by experimental reactivity measurements and molecular electronic structure calculations, within the framework of the Density Functional Theory and the Random Phase Approximation methods. The crucial role of alkene coordination and the origin of enantioselectivity are discussed. Two possible mechanisms are considered, via either prior hydride migratory insertion or boron migratory insertion. The minimum energy computed pathway leads to the enantiomer experimentally observed, therefore supporting the hydride migratory insertion mechanism. Calculations of the final steps of the catalytic cycle, i.e. regeneration of the catalyst and release of the product, give us further insights into the mechanism and rationalize the experimental results.
\end{abstract}

\section{Introduction}

Lewis base borane complexes, such as $\mathrm{BH}_{3} \cdot \mathrm{Me}_{2} \mathrm{~S}, \mathrm{BH}_{3} \cdot \mathrm{THF}^{1}$ and, in some cases, amine $^{2}$ or phosphine boranes, ${ }^{3}$ are efficient reagents for the stoichiometric and metal free-catalyzed hydroboration of olefins. In the last decade, development of more stabilized Lewis base borane complexes (unreactive in non-catalyzed hydroboration reactions) has become an attractive field of research. Accordingly, B-H bond activation at a metal center can lead to dehydropolymerization by means of dihydrogen gas release, predominantly with primary or secondary amine borane complexes (Scheme 1a). ${ }^{4}$ Besides their applications in the field of $\mathrm{H}_{2}$ storage/release, many applications in the polymer or materials science field involve boron-nitrogen compounds obtained from this reaction. ${ }^{5}$ Interestingly, a unique case of rhodium-catalyzed intermolecular hydroboration was reported by Weller and coworkers, with a tertiary amine borane complex $\left(\mathrm{BH}_{3} \cdot \mathrm{NMe}_{3}\right)$ in the presence of $t$-butylethylene (TBE) (Scheme 1b). ${ }^{6}$ Dehydrogenative boron-boron homocoupling reactions can also occur, ${ }^{7}$ as previously observed in limited examples of borane derivatives upon metal activation. ${ }^{8}$

Aix Marseille University, CNRS, Centrale Marseille, iSm2, Marseille, France. E-mail: paola.nava@univ-amu.fr, olivier.chuzel@univ-amu.fr

$\dagger$ Electronic supplementary information (ESI) available: Experimental procedures, spectroscopic data, and detailed calculations (energies and xyz coordinates). See DOI: 10.1039/C9DT03660A
B-H bond activation of amine-borane at a metal center has been widely studied and described. ${ }^{4}$ However, and when it comes to N-heterocyclic carbene (NHC) borane complexes, this area is underexplored. We have recently reported the prepa-

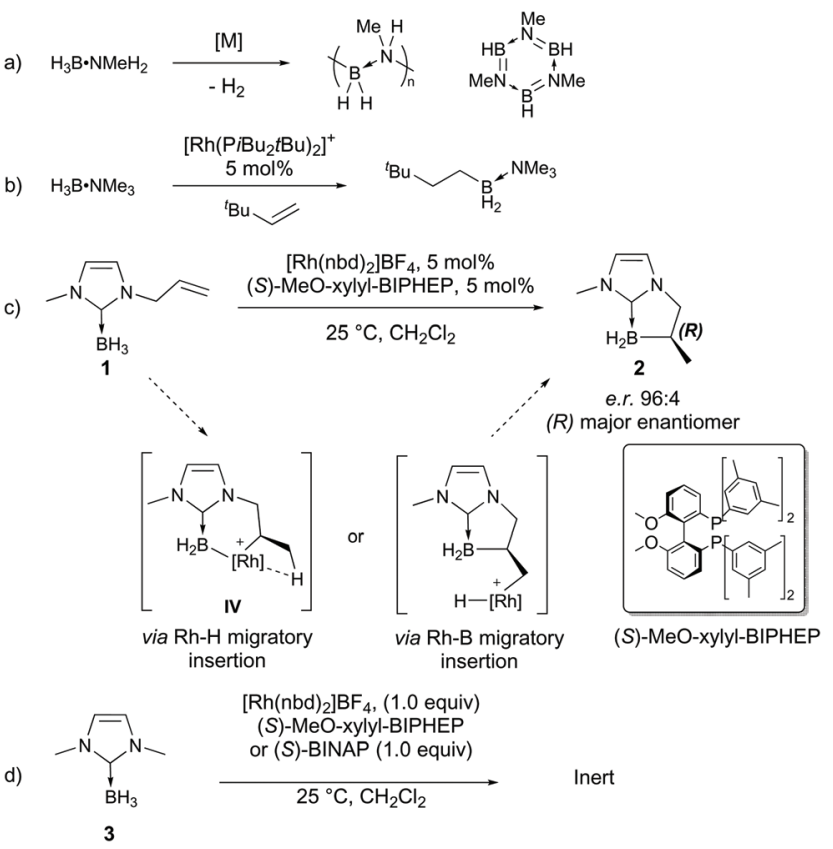

Scheme 1 Lewis base $\mathrm{BH}_{3}$ reactivity towards a metal center with or without the olefin. 
ration of cyclic NHC-boranes thanks to regio- and enantioselective hydroboration catalyzed by diphosphane-ligated cationic rhodium(l) complexes (Scheme 1c). ${ }^{9}$ This transformation allows us to prepare cyclic enantioenriched NHC-boranes. The scope of the reaction was broad, and the process was successfully applied to a range of allyl-substituted $\mathrm{BH}_{3} \cdot \mathrm{NHC}$ substrates. In the meantime, other groups have exploited the $\mathrm{B}-\mathrm{H}$ bond reactivity of NHC-boranes ${ }^{10}$ at a metal center ${ }^{11}$ (including metallo-enzymes ${ }^{12}$ ) or in ionic reactions. ${ }^{13}$ In addition, chiral NHC-borane scaffolds as catalyst precursors in borenium chemistry have emerged as a promising platform for reduction reactions in the new field of Frustrated Lewis Pairs (FLPs), ${ }^{14}$ thus attracting growing interest for the design of original chiral boron derivatives.

While metal catalyzed hydroboration using other $\mathrm{B}-\mathrm{H}$ sources (catechol boranes ${ }^{15}$ and tertiary amine borane complexes ${ }^{16}$ ) have been mechanistically described by kinetic or DFT studies, the B-H bond metal activation of NHC-boranes has not been investigated yet.

For a complete understanding of this activation process, complementary experiments ${ }^{9}$ and a theoretical treatment are presented in this paper. We discuss a pertinent mechanism of NHC-borane intramolecular hydroboration promoted by a cationic rhodium species (Scheme 1c). The crucial role of the NHC-borane/alkene substrate as a bidentate ligand and the origin of enantioselectivity are highlighted.

\section{Computational details}

This work focuses on the mechanism of intramolecular enantioselective hydroboration. In general, enantioselectivity can be due to (small) differences between diastereomeric transition states, notably when a specific mechanistic step (corresponding to a specific transition state) is clearly relevant for the kinetics of the reaction (Curtin-Hammett's conditions). In other cases, especially with large catalytic systems and for complex pathways, several transition states may become kinetically relevant. ${ }^{17}$ For both scenarios, accurate energy calculations are desirable. Furthermore, when the substrate is achiral and the reaction is enantioselective, the chirality transfer must be due to the interaction between the substrate and substituents of the bulky chiral ligand. Non-covalent interactions may become crucial for the energetics. Therefore, we perform our computational treatment within the Density Functional Theory (DFT) framework, by including empirical dispersion corrections: structures are optimized at the PBE level by employing D3 Grimme's empirical dispersion terms. ${ }^{18,19}$ Accurate electronic energies are obtained at the Random Phase Approximation (RPA) level. This method, which has experienced in the last decade a revival as a promising post-Kohn-Sham method to treat electron correlation, improves upon standard DFT for the description of noncovalent interactions as it avoids the introduction of empirically parametrized terms (see ESI $\dagger$ for comparison with other methods). ${ }^{20-22}$
Calculations are performed with the program package TURBOMOLE. ${ }^{23}$ A scalar relativistic ECP is employed for the rhodium atom. ${ }^{24}$ The basis set for optimization is of def2TZVP quality. ${ }^{25}$ The nature of the stationary points is checked by frequency calculations. Reported energies are single-point calculations at the RPA level, with the PBE functional and a def2-QZVP basis set. ${ }^{20,25}$ For all calculations, relevant speed-up is achieved by employing the resolution of the identity technique. ${ }^{26}$ Gibbs free-energy corrections are added as obtained at the optimization level.

\section{Results and discussion}

As recently described by our group, NHC-boranes, which are unreactive in non-catalyzed hydroboration reactions, undergo exclusively intramolecular hydroboration in the presence of a diphosphane-ligated cationic rhodium complex (Scheme 1c). ${ }^{9}$ Two commonly assumed mechanisms have been considered here, via either the [Rh]-H or the [Rh]-B migratory insertion steps. ${ }^{15}$ In order to be as exhaustive as possible, we have computed both mechanisms, either in their pro- $(R)$ or pro- $(S)$ versions. The origin of enantioselectivity is then disclosed based on the structural analysis of the key intermediates.

\section{Experimental investigations}

In the catalytic cycle, we hypothesize that the two norbornadiene (NBD) ligands of $\left[\mathrm{Rh}(\mathrm{NBD})_{2}\right] \mathrm{BF}_{4}$ are exchanged by the chiral diphosphine ( $\mathrm{L}=(S)$-MeO-xylyl-BIPHEP) and by substrate $\mathbf{1}$, in large excess compared to the catalyst loading used in the procedure (Scheme 1c). NHC-borane $\mathbf{1}$ can coordinate the rhodium center both with the olefin and an agostic B-H$\mathrm{Rh}$ three-center two-electron bond. The latter feature has been already demonstrated by Braunschweig for molybdenum, tungsten, chromium and manganese NHC-borane complexes. ${ }^{27}$

Before proceeding with the computational treatment, several experiments are carried out to clarify the role of NHCborane $\mathbf{1}$ as a bidentate ligand.

The kinetic rate of the reaction (below $1 \mathrm{~min}$ ) does not allow us to observe any rhodium complex intermediates by ${ }^{1} \mathrm{H}$ NMR spectroscopy in the catalytic procedure. In order to observe the hypothetical B-H-Rh three-center two-electron bonding, NHC-borane 3, without the allyl substituent (Scheme 1d), is used as a model substrate. However, and interestingly, the reaction mixture is found to be inert, even with a stoichiometric amount of rhodium complex $\left[\mathrm{Rh}(\mathrm{NBD})_{2}\right] \mathrm{BF}_{4}$ and $(S)$-MeO-xylyl-BIPHEP or $(S)$-BINAP as a ligand.t Unlike in the report of Braunschweig and co-workers, ${ }^{27}$ the "Shimoitype" $\sigma$-borane complex is not observed. ${ }^{28}$ As a control experiment, stoichiometric addition of $(S)$-BINAP $\$$ to $\left[\mathrm{Rh}(\mathrm{NBD})_{2}\right] \mathrm{BF}_{4}$ in dichloromethane yields the $[\mathrm{Rh}(\mathrm{NBD})((S)-\mathrm{BINAP})] \mathrm{BF}_{4}$ complex with full conversion and the release of one equivalent

$\ddagger$ The catalytic procedure with $(S)$-BINAP gave comparable results to $(S)$-MeOxylyl-BIPHEP. To reduce the catalytic system cost, (S)-BINAP is used in stoichiometric experiments. 
of norbornadiene. Next, the addition of 1.0 or 3.0 equiv. of NHC-borane 3 does not reveal any interaction between the rhodium complex and NHC-borane at the ${ }^{1} \mathrm{H}$ NMR time scale (see $\mathrm{ESI}_{\dagger} \dagger$ ). These experiments suggest that the coordination of the olefin moiety is needed for concomitant $\mathrm{B}-\mathrm{H}$ bond activation at the metal center in this intramolecular process. These results strongly support our previous mechanistic investigation: scrambling studies demonstrated that the hydroboration process is fully intramolecular, without the migration of hydride or deuteride via hypothetical [Rh]-H/-D exchange. ${ }^{9}$

Finally, the role of the diphosphine ligand is investigated. A mixture of NHC-borane 3 (1.0 or 3.0 equiv.) with the rhodium complex $\left[\mathrm{Rh}(\mathrm{NBD})_{2}\right] \mathrm{BF}_{4}$ without $(S)$-MeO-xylyl-BIPHEP or $(S)$ BINAP as a ligand yields a spontaneous precipitate of black rhodium species and a complex mixture of by-products is observed by ${ }^{1} \mathrm{H}$ and ${ }^{11} \mathrm{~B}$ NMR. This experiment clearly shows that the bulky diphosphine ligand drives the chemoselectivity and inhibits the formation and the reactivity of $\sigma$-NHC-borane complexes towards dihydrogen release. In conclusion, we assume that in the case of NHC-borane $\mathbf{1}$, the concomitant olefin and $\mathrm{B}-\mathrm{H}$ coordination stabilizes the rhodium cationic complex, thus preventing the dehydrogenation process. Then, the subsequent coordination of the diphosphine ligand leads to the intramolecular hydroboration catalytic process.

\section{Computational treatment}

Results for the computed reaction profiles are shown in Fig. 1. Given that the enantioselectivity is a consequence of the chiral bulky diphosphine ligand on the rhodium center, we could not reduce the size of the system and we had to consider the whole rhodium complex in the calculations. When necessary and for clarity reasons, the subscripts $(R)$ and $(S)$ are employed to indicate the pro- $(R)$ and pro- $(S)$ intermediates, respectively.

The energy of complex $\mathbf{0}$ is chosen as reference in Fig. 1, because its structure is not selective towards the pro- $(R)$ and pro- $(S)$ paths, as the alkene moiety does not bind to the metal. The coordination of the alkene to the rhodium center can lead to several structures: in $\mathbf{I}\left(\mathbf{I}_{\boldsymbol{R}}\right.$ or $\left.\mathrm{I}_{S}\right)$ the alkene moiety is (approximately) in the $\mathrm{P}-\mathrm{Rh}-\mathrm{P}$ plane, whereas in the reactive conformations $\mathbf{I I}\left(\mathbf{I I}_{R}\right.$ or $\left.\mathbf{I I}_{S}\right)$, it is orthogonal to this plane, to minimize the distance to $-\mathrm{BH}_{3}$. The experimental investigations show that the catalytically active species is a complex in which the $\mathrm{B}-\mathrm{H}$ bond and the alkene moieties connect to rhodium. Indeed, their vicinity to the substrate allows for easy double coordination of the metal: the barriers from $\mathbf{0}$ to I and/ or II are low (between 2 and $8 \mathrm{kcal} \mathrm{mol}^{-1}$ ) and equilibria are possible at this stage. Intermediates $\mathbf{I}_{S}$ or $\mathbf{I I}_{\boldsymbol{S}}$ have almost the same Gibbs free-energy as $\mathbf{0}$ and they can also evolve into the most stable intermediates $\mathbf{I}_{\boldsymbol{R}}$ or $\mathbf{I I}_{\boldsymbol{R}}$. Alternatively, another pathway is possible that connects directly $\mathbf{0}$ to II (Fig. 1, the solid blue line and the dashed red line). In the transition state to $\mathbf{I I}_{\boldsymbol{R}}\left(\mathbf{T s}_{\mathbf{0}-\mathbf{I}_{R}}\right)$ (Fig. 2), the alkene moiety approaches the metal center from the less sterically hindered quadrant. This is not the case for $\mathbf{T s}_{\mathbf{0}-\mathbf{I I}_{S}}$ (Fig. 2). The result is that the barrier to obtain the reactive intermediate $\mathbf{I I}_{R}$ is only $2.0 \mathrm{kcal} \mathrm{mol}^{-1}$ and it is the lowest barrier (Fig. 1, the solid blue line).



Fig. 2 Computed structures for the transition states leading from 0 to $I I_{R}$ and $I I_{S}\left(T_{0-1 I_{R}}\right.$ and $\mathrm{Ts}_{0-1 I_{s^{\prime}}}$ PBE-D3/def2-TZVP). The phenyl groups of the most hindered quadrants are indicated by thicker lines.

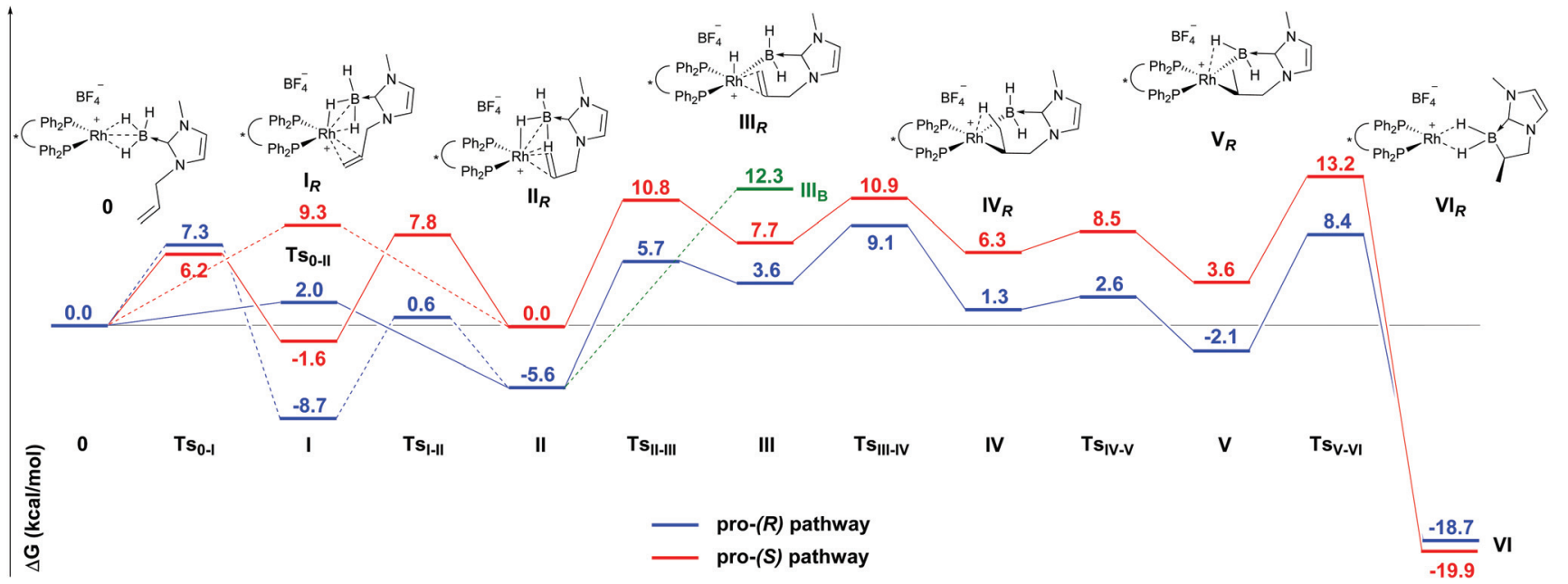

Fig. 1 Computed reaction profiles for the pro- $(S)$ and pro- $(R)$ mechanisms via the $[\mathrm{Rh}]-\mathrm{H}$ migratory insertion mechanism. III $\mathrm{B}$ represents the pro- $(R)$ hydride intermediate for the [Rh]-B migratory insertion mechanism. Gibbs-free-energies are relative to complex 0. Computational level: RPA(PBE)/ def2-QZVP//PBE-D3/def2-TZVP, Gibbs free-energy corrections at the optimization level. 
At first, for the $(R)$ enantiomer, which is the major product, the two commonly proposed mechanisms for the hydroboration are considered, via either the $[\mathrm{Rh}]-\mathrm{H}$ or the $[\mathrm{Rh}]-\mathrm{B}$ migratory insertion steps. However, in the [Rh]-B migratory insertion mechanism the hydride initially formed in the apical position (Fig. 1, intermediate $\mathbf{~ I I I}_{\mathbf{B}}$, in green) is higher in energy than all the transition states of the pro- $(R)[\mathrm{Rh}]-\mathrm{H}$ migratory insertion mechanism $\left(12.3 \mathrm{kcal} \mathrm{mol}^{-1}\right.$ with respect to $\left.\mathbf{0}\right)$. Since its formation is clearly disfavored, we shall not discuss this pathway in detail, and we shall compare the pro- $(R)$ and pro- $(S)$ mechanisms via the $[\mathrm{Rh}]-\mathrm{H}$ migratory insertion step. For further details of the mechanism through the [Rh]-B migratory insertion step, see the ESI. $\dagger$

[Rh-H] migratory insertion mechanism and the origin of enantioselectivity. The coordination patterns around the rhodium center of the reactive intermediates II are very similar for $\mathbf{I I}_{\boldsymbol{R}}$ and $\mathbf{I I}_{\boldsymbol{S}}$ (Fig. 3). However, the preference for the pro-( $R$ ) mechanism is evident here and the structural constraints that contribute to the $5.6 \mathrm{kcal} \mathrm{mol}^{-1}$ energy difference between $\mathbf{I I}_{R}$ and $\mathbf{I I}_{\boldsymbol{S}}$ are imposed by the chiral diphosphine. For a better understanding, the two intermediates are shown from the viewpoint of the $\mathrm{P}$ atom trans to the $-\mathrm{BH}_{3}$ moiety (Fig. 3). This view allows us to establish structural details that contribute to the energetics: in $\mathbf{I I}_{\boldsymbol{R}}$ the $\mathrm{C}(9)-\mathrm{Rh}$ bond is staggered with respect to the $\mathrm{P}(1)$-phenyl bonds (dihedral angle $\mathrm{C}(9)-\mathrm{Rh}-\mathrm{P}$ (1) $-\mathrm{C}_{R}=-69.6^{\circ}$, Fig. 3), reducing the repulsion between the substrate and the diphosphine. In $\mathbf{I I}_{\boldsymbol{S}}$ the $\mathrm{C}(9)-\mathrm{Rh}$ bond is eclipsed (dihedral angle $\mathrm{C}(9)-\mathrm{Rh}-\mathrm{P}(2)-\mathrm{C}_{S}=0.4^{\circ}$, Fig. 3), and thus steric repulsion is larger than that for the other diastereo-

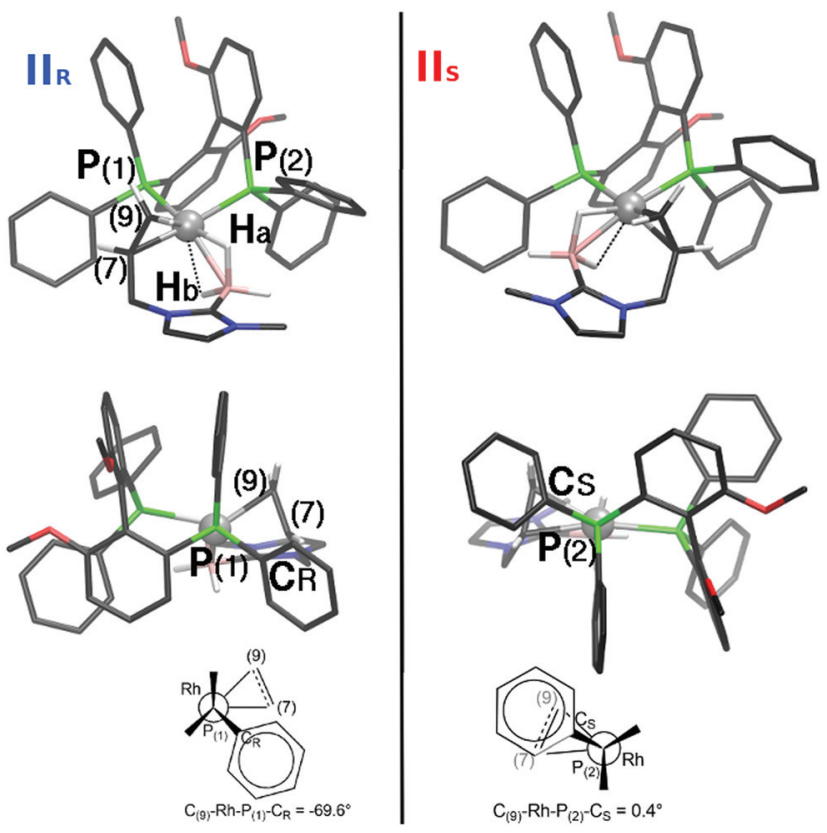

Fig. 3 Computed structures of diastereomers $A_{R}$ and $A_{S}$ (PBE-D3/def2TZVP (evel). At the top, the structures are presented from the reactive side, and at the bottom from the diphosphine side, along the $\mathrm{P}-\mathrm{Rh}$ bond, where the $\mathrm{P}$ atom is trans to the $-\mathrm{BH}_{3}$ moiety of the substrate. Sketches of the relevant atoms are reported. mer. This conformational analysis is the same as that for the other intermediates. From II, an endothermic step leads to the formation of rhodium-hydrides III. In these intermediates, rhodium has a square-pyramidal environment: the $\mathrm{NHC}^{-\mathrm{BH}_{2}}$ fragment is ligated through the boron to the rhodium atom in the apical position, while the $\mathrm{H}$ atom, the alkene moiety and the diphosphine ligand occupy the other (equatorial) positions. This transformation requires overcoming the transition states located at +5.7 and $+10.8 \mathrm{kcal} \mathrm{mol}^{-1}$ for the pro- $(R)$ and the pro- $(S)$ pathways, respectively. The rhodium-hydrides are destabilized with respect to intermediates II by $9.1 \mathrm{kcal} \mathrm{mol}^{-1}$ (pro- $(R)$ ) and $7.7 \mathrm{kcal} \mathrm{mol}^{-1}$ (pro- $(S)$ ) and they readily connect to the alkene by forming the terminal $-\mathrm{CH}_{3}$ group, which occupies approximately the position of the former hydride IV. Barriers are $5.5 \mathrm{kcal} \mathrm{mol}^{-1}$ (pro- $(R)$ ) and $3.2 \mathrm{kcal} \mathrm{mol}^{-1}$ (pro- $(S)$ ). Easy conformational changes are needed (a barrier of $2 \mathrm{kcal} \mathrm{mol}^{-1}$ ) to release $-\mathrm{CH}_{3}$ from the metal and to move the $-\mathrm{BH}_{2}$ fragment off from the apical to a pseudo-equatorial position $\mathbf{V}$. The reductive elimination step follows, leading to the product, coordinated to the rhodium atom VI (Scheme 2).

The highest transition states are located at $+9.1 \mathrm{kcal} \mathrm{mol}^{-1}$ for the pro- $(R)$ path $\left(\mathbf{T s}_{\text {III-IV }}\right.$, insertion step) and at $+13.2 \mathrm{kcal}$ $\mathrm{mol}^{-1}$ for the pro- $(S)$ path $\left(\mathbf{T s}_{\mathbf{V}-\mathbf{V} \mathbf{I}}\right.$, reductive elimination), suggesting that the reactions are facile. Interestingly, the reductive elimination transition states are only 13.9 and $13.2 \mathrm{kcal} \mathrm{mol}^{-1}$ higher in Gibbs free-energy than the reactive $\mathbf{I I}_{R}$ and $\mathbf{I I}_{S}$ intermediates.

In a model system, where the phosphine is less hindered, the largest barrier is for the reductive elimination step, as the transition state is $19.0 \mathrm{kcal} \mathrm{mol}^{-1}$ higher in energy than the

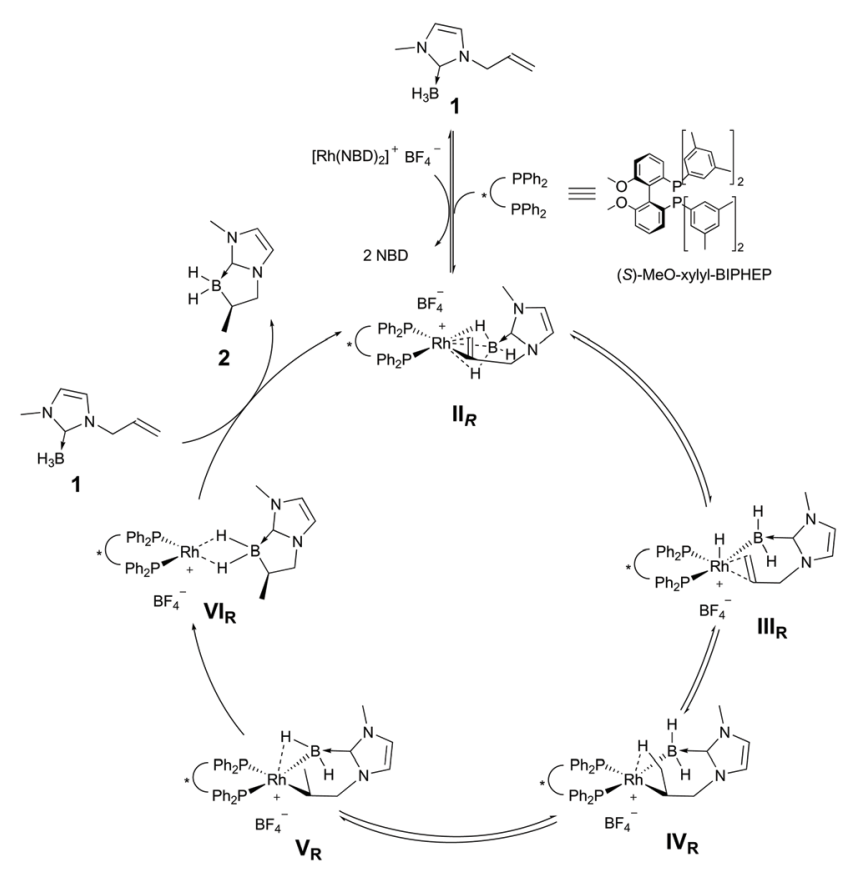

Scheme 2 The proposed catalytic cycle for NHC-borane 1 intramolecular hydroboration reaction promoted by a cationic rhodium species. 
corresponding structure of II (see ESI $\dagger$ ). As expected, the bulkiness of the diphosphane ligand has an influence: while an increase of the metal coordination number is obtained by rhodium-hydride formation, the reductive elimination implies a decrease in the hindrance around the rhodium atom and the corresponding barrier height is slightly reduced by the crowded environment.

Finally, the main result from Fig. 1 is that the computed pro- $(R)[\mathrm{Rh}]-\mathrm{H}$ migratory insertion pathway is globally energetically lower than the pro- $(S)$ pathway: the energetic preference for pro- $(R)$ is remarkable for intermediates $\mathbf{I I}_{\boldsymbol{R}}$ and $\mathbf{I I}_{\boldsymbol{S}}$ (Fig. 3) and is maintained for IV and $\mathbf{V}$. However, some $(S)$ product is obtained and it could be explained by the general procedure: $\left[\mathrm{Rh}(\mathrm{NBD})_{2}\right] \mathrm{BF}_{4}$, the chiral diphosphine and the substrate are mixed all together and then solvent is added. Due to its higher concentration, the substrate could easily form a pre-complex with $\left[\mathrm{Rh}(\mathrm{NBD})_{2}\right] \mathrm{BF}_{4}$ and the substitution of at least an NBD by the substrate would follow. At this stage, the substrate could coordinate to the metal center in a pro- $(S)$ or pro- $(R)$ fashion and the reaction could take place from here $\left(\left[\mathrm{Rh}(\mathrm{NBD})_{2}\right] \mathrm{BF}_{4}\right.$ catalyzes slowly the reaction in a racemic manner, see ref. 9).

Product formation and the start of the second catalytic cycle. The coordination of a new substrate molecule releases the final product. We then computed pathways for the substitution of a final $R$ product by a new substrate (Fig. 4). We do not claim to be exhaustive for the description of steps VI to I; the aim is to show that this replacement is possible, and the catalytic cycle can be repeated. Gibbs free-energies are relative

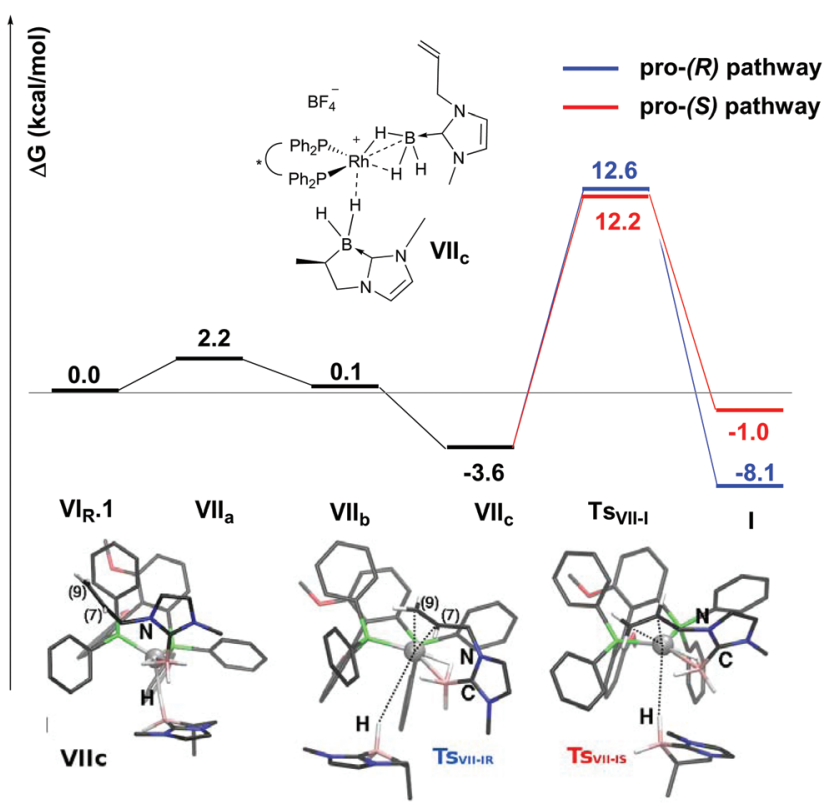

Fig. 4 Computed energetics profiles for the substitution of the final $R$ product by a new substrate 1 . The substrate approaches by the $\mathrm{BH}_{3}$ moiety. Energies are relative to a computed super-structure of $\mathrm{VI}_{R}$, in which the substrate is in the second coordination sphere of the complex. The computed structures of $\mathrm{VII}_{\mathrm{C}}, \mathrm{Ts}_{\mathrm{VII}-\mathrm{I}_{R}}$ and $\mathrm{Ts}_{\mathrm{VII}-\mathrm{I}_{\mathrm{S}}}$ are depicted ( $\mathrm{P}$ atoms in green, the PBE-D3/def2-TZVP level). to a computed super-structure of $\mathbf{V I}_{\boldsymbol{R}}$, in which the substrate is in the second coordination sphere of the complex $\left(\mathbf{V I}_{R} \cdot \mathbf{1}\right)$. As several mechanisms are possible, we have only considered two main approaches for product substitution: by the alkene or by the $-\mathrm{BH}_{3}$ moieties of $\mathbf{1}$. The first approach is intrinsically pro$(R)$ or pro- $(S)$, since the diastereoselectivity of the rhodium complexes is installed through alkene coordination. It is clearly disfavored for the pro- $(R)$ path, with a barrier of $18.7 \mathrm{kcal} \mathrm{mol}^{-1}$, but it is possible for the pro-(S) path (the computed larger barrier is $8.5 \mathrm{kcal} \mathrm{mol}^{-1}$, see ESI $\dagger$ ).

In the second approach (Fig. 4), the substrate connects firstly to the rhodium center by a hydrogen atom of the $-\mathrm{BH}_{3}$ moiety in a barrierless step, $\mathbf{V I I}_{\mathbf{a}}$. Some conformational changes take place, for which we have not computed the transition states, and intermediate $\mathbf{V I I}_{\mathbf{c}}$ is obtained, in which the incoming NHC-borane $\mathbf{1}$ is connected by the $-\mathrm{BH}_{3}$ moiety. The product occupies an apical position, and it is loosely bound to the metal complex by a rather long $\mathrm{Rh}-\mathrm{H}$ bond $(178 \mathrm{pm}$, Fig. 4). This intermediate is formally not discriminatory for the product chirality. The following transition states, either $\mathbf{T s}_{\mathbf{V I I}_{\mathrm{II}} \mathrm{I}_{R}}$ or $\mathbf{T s}_{\mathrm{VII}-\mathrm{I}_{S}}$, show one imaginary vibrational mode in which the alkene approaches the metal and the product moves away. We notice, however, that they are late with respect to the removal of the product, since distances to the rhodium are $388 \mathrm{pm}$ and $351 \mathrm{pm}$ respectively for the pro- $(R)$ and the pro- $(S)$ pathways (Fig. 4). Barriers to either the pro- $(R)$ or the pro- $(S)$ pathways are accessible and very close in energy, as the transition states are located at $+12.2 \mathrm{kcal} \mathrm{mol}^{-1}$ and +12.6 $\mathrm{kcal} \mathrm{mol}^{-1}$, respectively. However, we have seen that the interconversion from the pro- $(S)$ to the pro- $(R)$ pathway is possible through intermediate $\mathbf{0}$ (Fig. 1).

\section{Conclusions}

This contribution, which combines experimental and theoretical approaches, provides insights into the peculiar behavior of allyl-NHC-boranes and discloses the relevant mechanistic pathway leading to the experimentally observed enantiomer. Unlike other Lewis-base stabilized $\mathrm{BH}_{3}$ complexes, allyl-NHCboranes undergo intramolecular hydroboration in the presence of a rhodium catalyst via $\mathrm{B}-\mathrm{H}$ bond activation. The vicinity of the alkene moiety to the NHC ring allows for efficient simultaneous coordination of the metal by the alkene moiety and by $\mathrm{BH}_{3}$ (intermediates $\mathbf{I}$ and $\mathbf{I I}$ ). The coordination of the double bond to the rhodium atom in a pro- $(R)$ fashion (orthogonal to the $\mathrm{P}-\mathrm{Rh}-\mathrm{P}$ plane) is crucial. We showed that the reaction leading to the formation of the major $(R)$ product proceeds by a mechanism that starts with an $[\mathrm{Rh}]-\mathrm{H}$ migratory insertion step, followed by reductive elimination (Scheme 2). The pro- $(R)$ pathway is overall energetically lower than the pro- $(S)$ pathway. The interaction between the substrate and the chiral diphosphine implies that $\mathbf{T s}_{\mathbf{0}-\mathbf{I}_{R}}$ is low in energy (according to the quadrant rule). Moreover, structures along the pro- $(R)$ path are more stable, due to their staggered conformations. 


\section{Conflicts of interest}

There are no conflicts to declare.

\section{Acknowledgements}

The authors gratefully acknowledge the French Research Ministry (Grant 2010-2013, M. T.), Aix Marseille University, and CNRS (UMR 7313) and the Agence Nationale de la Recherche (ANR-16-CE07-0002-01) for support.

\section{Notes and references}

1 H. C. Brown and B. C. Subba Rao, J. Am. Chem. Soc., 1956, 78, 2582.

2 J. V. B. Kanth, Aldrichimica Acta, 2002, 35, 57; M. Scheideman, G. Wang and E. Vedejs, J. Am. Chem. Soc., 2008, 130, 8669; A. Staubitz, A. P. M. Robertson, M. E. Sloan and I. Manners, Chem. Rev., 2010, 110, 4023.

3 A. C. Gaumont, K. Bourumeau, J. M. Denis and P. Guenot, J. Organomet. Chem., 1994, 484, 9; H. Schmidbaur, M. Sigl and A. Schier, J. Organomet. Chem., 1997, 529, 323; P. Shapland and E. Vedejs, J. Org. Chem., 2004, 69, 4094.

4 Selected reviews: A. Rossin and M. Peruzzini, Chem. Rev., 2016, 116, 8848; A. L. Colebatch and A. S. Weller, Chem. Eur. J., 2019, 25, 1379; D. Han, F. Anke, M. Trose and T. Beweries, Coord. Chem. Rev., 2019, 380, 260; R. L. Melen, Chem. Soc. Rev., 2016, 45, 775; R. J. Less, R. L. Melen and D. S. Wright, RSC Adv., 2012, 2, 2191.

5 S. Bhunya, T. Malakar, G. Ganguly and A. Paul, ACS Catal., 2016, 6, 7907; H. C. Johnson, T. N. Hooper and A. S. Weller, in Synth. Appl. Organoboron Compd, ed. E. Fernández and A. Whiting, Springer, Cham, 2015, pp. 153-220.

6 L. J. Sewell, A. B. Chaplin and A. S. Weller, Dalton Trans., 2011, 40, 7499.

7 H. C. Johnson, C. L. McMullin, S. D. Pike, S. A. Macgregor and A. S. Weller, Angew. Chem., Int. Ed., 2013, 52, 9776; H. C. Johnson, E. M. Leitao, G. R. Whittel, I. Manners, G. C. Lloyd-Jones and A. S. Weller, J. Am. Chem. Soc., 2014, 136, 9078.

8 E. W. Corcoran and L. G. Sneddon, J. Am. Chem. Soc., 1984, 106, 7793; O. Ciobanu, E. Kaifer, M. Enders and H.-J. Himmel, Angew. Chem., Int. Ed., 2009, 48, 5538; H. Braunschweig and F. Guethlein, Angew. Chem., Int. Ed., 2011, 50, 12613.

9 M. Toure, O. Chuzel and J.-L. Parrain, J. Am. Chem. Soc., 2012, 134, 17892.

10 Q. Zhao, R. D. Dewhurst, H. Braunschweig and X. Chen, Angew. Chem., Int. Ed., 2019, 58, 3268.

11 D. P. Curran, A. Solovyev, M. Makhlouf Brahmi, L. Fensterbank, M. Malacria and E. Lacôte, Angew. Chem., Int. Ed., 2011, 50, 10294; Q.-Q. Cheng, S.-F. Zhu, Y.-Z. Zhang, X.-L. Xie and Q.-L. Zhou, J. Am. Chem. Soc., 2013, 135, 14094; X. Li and D. P. Curran, J. Am. Chem. Soc., 2013, 135, 12076;
T. H. Allen and D. P. Curran, J. Org. Chem., 2016, 81, 2094; D. Chen, X. Zhang, W.-Y. Qi, B. Xu and M.-H. Xu, J. Am. Chem. Soc., 2015, 137, 5268; Q. Chu, M. Makhlouf Brahmi, A. Solovyev, S.-H. Ueng, D. P. Curran, M. Malacria, L. Fensterbank and E. Lacôte, Chem. - Eur. J., 2009, 15, 12937; J. Monot, M. Makhlouf Brahmi, S.-H. Ueng, C. Robert, M. Desage-El Murr, D. P. Curran, M. Malacria, L. Fensterbank and E. Lacôte, Org. Lett., 2009, 11, 4914.

12 S. B. J. Kan, X. Huang, Y. Gumulya, K. Chen and F. H. Arnold, Nature, 2017, 552, 132; K. Chen, X. Huang, S.-Q. Zhang, A. Z. Zhoua, S. B. J. Kan, X. Hong and F. H. Arnold, Synlett, 2019, 378.

13 D. M. Lindsay and D. McArthur, Chem. Commun., 2010, 46, 2474; T. Watanabe, S. J. Geib, D. P. Curran and T. Taniguchi, J. Org. Chem., 2017, 82, 13034; D. A. Bolt and D. P. Curran, J. Org. Chem., 2017, 82, 13746; K. Nozaki, Y. Aramaki, M. Yamashita, S.-H. Ueng, M. Malacria, E. Lacôte and D. P. Curran, J. Am. Chem. Soc., 2010, 132, 11449; A. Solovyev, Q. Chu, S. J. Geib, L. Fensterbank, M. Malacria, E. Lacôte and D. P. Curran, J. Am. Chem. Soc., 2010, 132, 15072 .

14 J. Lam, K. M. Szkop, E. Mosaferi and D. W. Stephan, Chem. Soc. Rev., 2019, 48, 3592; P. Eisenberger and C. M. Crudden, Dalton Trans., 2017, 46, 4874; J. Lam, B. A. R. Günther, J. M. Farrell, P. Eisenberger, B. P. Bestvater, P. D. Newman, R. L. Melen, C. M. Crudden and D. W. Stephan, Dalton Trans., 2016, 45, 15303; C. Aupic, A. Abdou Mohamed, C. Figliola, P. Nava, B. Tuccio, G. Chouraqui, J.-L. Parrain and O. Chuzel, Chem. Sci., 2019, 10, 6524; P. Eisenberger, R. Melen, C. Crudden and D. W. Stephan, Dalton Trans., 2016, 45, 15303; D. M. Mercea, M. G. Howlett, A. D. Piascik, D. J. Scott, A. Steven, A. E. Ashleya and M. J. Fuchter, Chem. Commun., 2019, 55, 7077.

15 J. M. Brown, in Modern Rhodium-Catalyzed Organic Reactions, ed. P. A. Evans, Wiley-VCH, Weinheim, 2004, pp. 33-51; K. Burgess, W. A. van der Donk, S. A. Westcott, T. B. Marder, R. T. Baker and J. C. Calabrese, J. Am. Chem. Soc., 1992, 114, 9350; S. A. Westcott, H. P. Blom, T. B. Marder and T. Baker, J. Am. Chem. Soc., 1992, 114, 8863; R. T. Baker, J. C. Calabrese, S. A. Westcott, P. Nguyen and T. B. Marder, J. Am. Chem. Soc., 1993, 115, 4367; D. A. Evans, G. C. Fu and B. A. Anderson, J. Am. Chem. Soc., 1992, 114, 6679; D. R. Edwards, Y. B. Hleba, C. J. Lata, L. A. Calhoun and C. M. Crudden, Angew. Chem., Int. Ed., 2007, 46, 7799; A. E. Dorigo and P. von Ragué Schleyer, Angew. Chem., Int. Ed., 1995, 34, 115; C. Widauer, H. Grützmacher and T. Ziegler, Organometallics, 2000, 19, 2097; E. Daura-Oller, A. M. Segarra, J. M. Poblet, C. Claver, E. Fernández and C. Bo, J. Org. Chem., 2004, 69, 2669; Z.-D. Yang, R. Pal, G. L. Hoang, X. C. Zeng and J. M. Takacs, ACS Catal., 2014, 4, 763; S. A. Westcott, H. P. Blom, T. B. Marder, R. T. Baker and J. C. Calabrese, Inorg. Chem., 1993, 32, 2175; K. Burgess and M. Jaspars, Tetrahedron Lett., 1993, 34, 6813; H. Wadepohl, Angew. Chem., Int. Ed., 1997, 36, 2441; A.-M. Carroll, 
T. P. O'Sullivan and P. J. Guiry, Adv. Synth. Catal., 2005, 347, 609.

16 H. C. Johnson, R. Torry-Harris, L. Ortega, R. Theron, J. S. McIndoe and A. S. Weller, Catal. Sci. Technol., 2014, 4, 3486.

17 K. H. Hopmann, Int. J. Quantum Chem., 2015, 115, 1232.

18 S. Grimme, J. Antony, S. Ehrlich and H. Krieg, J. Chem. Phys., 2010, 132, 154104.

19 P. A. M. Dirac, Proc. R. Soc. London, Ser. A, 1929, 123, 714; J. C. Slater, Phys. Rev., 1951, 81, 385; J. P. Perdew and Y. Wang, Phys. Rev. B: Condens. Matter Mater. Phys., 1992, 45, 13244; J. P. Perdew, K. Burke and M. Ernzerhof, Phys. Rev. Lett., 1996, 77, 3865.

20 H. Eshuis, J. E. Bates and F. Furche, Theor. Chem. Acc., 2012, 131, 1084; J. Chedid, N. M. Ferrara and H. Eshuis, Theor. Chem. Acc., 2018, 137, 158.

21 C. Waitt, N. M. Ferrara and H. Eshuis, J. Chem. Theory Comput., 2016, 12, 5350.

22 S. Grimme, J. Chem. Phys., 2006, 124, 034108.

23 TURBOMOLE V7.0 2015, a development of the University of Karlsruhe and Forschungszentrum Karlsruhe $\mathrm{GmbH}$,
1989-2007, TURBOMOLE GmbH, since 2007; available from http://www.turbomole.com.

24 D. Andrae, U. Haeussermann, M. Dolg, H. Stoll and H. Preuss, Theor. Chim. Acta, 1990, 77, 123.

25 F. Weigend and R. Ahlrichs, Phys. Chem. Chem. Phys., 2005, 7, 3297.

26 F. Weigend, Phys. Chem. Chem. Phys., 2006, 8, 1057; A. Hellweg, C. Hättig, S. Höfener and W. Klopper, Theor. Chem. Acc., 2007, 117, 587.

27 P. Bissinger, H. Braunschweig, T. Kupfer and K. Radacki, Organometallics, 2010, 29, 3987.

28 M. Shimoi, S. Nagai, M. Ichikawa, Y. Kawano, K. Katoh, M. Uruichi and H. J. Ogino, J. Am. Chem. Soc., 1999, 121, 11704; Z. Lin in Tansition Metal $\sigma$-Borane Complexes, Contemporary Metal Boron Chemistry I, ed. T. B. Marder and Z. Lin, Springer, 2008, pp. 123-148; G. Alcaraz and S. Sabo-Etienne, Angew. Chem., Int. Ed., 2010, 49, 7170; W. H. Lam, S. Shimada, A. S. Batsanov, Z. Lin, T. B. Marder, J. A. Cowan, J. A. K. Howard, S. A. Mason and G. J. McIntyre, Organometallics, 2003, 22, 4557. 